\title{
MULHERES DE VELHICES DISSIDENTES E SEXUALIDADES TRANSGRESSORAS
}

\section{DISSIDENT OLD WOMEN AND TRANSGRESSING SEXUALITIES}

\begin{abstract}
Alice Alves Menezes Ponce de Leão ${ }^{1}$
RESUMO

A vivência da sexualidade feminina na velhice está ligada diretamente à história de vida das mulheres. Os fatores impeditivos ou reativadores da sexualidade estão condicionados menos em razão de fatores biofisiológicos e mais em relação à forma como as mulheres idosas elaboram e ressignificam a sua condição feminina ao longo do tempo e na velhice. A gestão contemporânea da velhice e as lutas feministas se constituem enquanto vias emancipatórias para a realização de uma sexualidade prazerosa até o final da vida. Este trabalho mergulha na teoria feminista para elaborar uma análise do papel transgressor que a mulher idosa vem protagonizando no desenho de uma velhice dissidente a partir do exercício da sua sexualidade.
\end{abstract}

Palavras-chaves: Velhice. Gênero. Sexualidade.

ABSTRACT

The experience of female sexuality in old age is directly linked to the women's life story. The factors that prevent or reactivate sexuality are conditioned less because of biophysiological factors and more in relation to the way in which elderly women elaborate and reframe their feminine condition over time and in old age. The contemporary management of old age and feminist struggles are constituted as emancipatory ways for the realization of a pleasurable sexuality until the end of life. This work dives into the feminist theory to elaborate an analysis of the transgressive role that the elderly woman has been playing in the design of a dissident old age from the exercise of her sexuality.

Keywords: Old age. Woman. Sexuality.

\section{INTRODUÇÃO}

A formação social da Amazônia é fortemente marcada por lastros sexistas que imputam sobre a mulher dessa região uma imagem pejorativamente sexualizada fazendo com que ela seja vulgarmente conhecida como mulher fácil, lascíva e parideira (TORRES, 2005). Essa forma

\footnotetext{
1 Assistente Social. Doutora em Processos Socioculturais na Amazônia, Mestre em Serviço Social e Sustentabilidade na Amazônia. Professora do Curso de Serviço Social da Universidade Federal do Amazonas. Integrante do Grupo de Estudo, Pesquisa e Observatório Social: Gênero, Política e Poder (GEPOS). e-mail: allicyponce@gmail.com
} 
de depreciação constitui-se em uma violência moral ancorada numa ideia construída na sociedade colonial, especialmente a partir do século XVIII quando ocorre o povoamento da região, sob os auspícios da era pombalina.

As mulheres do Amazonas, em geral, apresentam um comportamento acolhedor tratando as pessoas por "mano" ou "mana" (redução afetuosa de "irmão"), são caladas, contidas e falam muito baixo. Esse comportamento é vulgarizado e, portanto, confundido como mulheres sonsas, atiradas e que roubam maridos das outras. Soma-se o fato de a maioria da população amazonense ser composta por mulheres.

$\mathrm{Na}$ capital Manaus, as mulheres industriárias são as que mais sofrem esse tipo de preconceito. Nas empresas onde trabalham, sofrem assédio sexual e moral para ascenderem de cargo e se engravidam. De acordo com Torres (2005), trata-se de uma estratégia sexista do capital para a desmobilização do poder político das mulheres em suas lutas por melhores condições de trabalho. Se na capital as mulheres são vulgarmente sexualizadas, essa depreciação se acentua ainda mais em relação às mulheres do interior do Amazonas.

Em Parintins, distante a $369 \mathrm{~km}$ da capital Manaus, a sexualização das mulheres está diretamente atrelada a imagem do festival folclórico dos bois-bumbás garantido e caprichoso que ocorre todo ano no mês de junho. Trata-se de um grande espetáculo no meio da floresta que atrai milhares de turistas brasileiros e estrangeiros. Nessa festa, as personagens femininas ganham destaque representando a mulher indígena, com realces de sensualidade e beleza. No período em que ocorre a festa na cidade, é comum ver pessoas andando seminuas nas ruas e após o término do festival, constata-se sempre o aumento do número de doenças sexualmente transmissíveis e gravidez.

A imagem sexualizada da mulher de Parintins não tem recorte etário, ou seja, não se restringe às mulheres jovens de corpos esculturais, mas contempla as mulheres velhas também. Na cidade, elas estão vulgarmente divididas entre as "sacanas" e as "de respeito" (PONCE DE LEÃO NONATO, 2018). As mulheres idosas que gozam de autonomia e independência e se permitem frequentar bailes de terceira idade, centros de convivência e que decidem namorar são chamadas de "sacanas", uma adjetivação pejorativa que retrata a transgressão do papel 
socialmente esperado para a mulher velha, de invisibilidade. Por outro lado, "as senhoras de respeito" são aquelas que somente frequentam igrejas e se dedicam aos cuidados do lar e da família.

Em uma cidade como Parintins em que a grande maioria de seu povo é pobre e vive do setor de comércios e serviços, é comum ver o envolvimento de homens mais velhos com mulheres mais jovens trocando sexo por bens de consumo ou por bens de necessidade imediata, como alimentação. Espera-se que as mulheres idosas, esposas ou não desses homens, resignemse ao sofrimento da infidelidade e reservem-se à castidade sexual podendo contentar-se, ao máximo, com o prazer de suas amizades.

Mas, as mulheres idosas desse contexto interiorano transgridem essas expectativas ao decidirem manter-se sexualmente ativas como os homens idosos. Assim como eles, elas preferem se envolver com pessoas mais jovens em busca de sexo embora vivam a sua sexualidade em suas múltiplas expressões, graças às ressignificações que a velhice vem assumindo nas últimas décadas sob o signo da terceira idade.

É nesse sentido que este trabalho apresenta um descortinamento da transgressão do papel de gênero protagonizado pelas mulheres idosas do contexto interiorano de uma cidade da Amazônia, Parintins, no estado do Amazonas. Para manter-se sexualmente ativas, essas mulheres idosas pobres acionam os artifícios do imaginário e do simbolismo dos rituais de pajelança indígena que se traduzem nos chás e nas garrafadas para a manutenção do vigor físico e, consequentemente, a disposição para o sexo enquanto na capital, as mulheres que se mantem sexualmente ativas recorrem aos artifícios da indústria farmacológica. É a partir da ressignificação do papel de gênero que essas mulheres idosas desse interior conseguem manter o exercício de suas sexualidades.

\section{A VELHICE TENSIONADA DAS MULHERES}

A teoria feminista tem dedicado pouca atenção às mulheres idosas. São raras as produções bibliográficas no campo de gênero que se debruçam sobre o marcador de geração. Os marcadores de diferença, como raça, classe social e geração, são importantes para a 


\section{Revista \\ Debates Insubmissos}

compreensão das assimetrias de poder que se inscrevem no contexto vivencial das mulheres e que aprofundam as estruturas de opressão e dominação, pois "[...] a opressão das mulheres possui uma forma singular, discernível na estrutura universal ou hegemônica da dominação patriarcal ou masculina" (BUTLER, 2019, p. 21).

O rito da velhice para as mulheres é marcado por um intenso processo de desvalorização. No discurso machista, mulher tem prazo de validade, isso quer dizer que o seu valor está circunscrito dentro de um período curto de tempo em que vigora a prevalência de certos atributos, como a beleza física e a capacidade reprodutiva. Diferente do homem idoso, que à medida que o tempo passa pode ser considerado mais charmoso e valorizado pelo seu prestígio social, a mulher idosa, além de ser desqualificada moralmente pela aparência envelhecida, se torna um fardo quando não oferece mais condições de cumprir com o papel de cuidadora.

De acordo com Debert (1994), como a mulher sempre foi valorizada pelo papel de reprodutora e de cuidado com as crianças, após o cumprimento desta função, ela é abandonada pelos filhos adultos. $\mathrm{O}$ avanço da idade pode trazer, ainda, um conjunto de outras perdas, como a viuvez, o isolamento, a depressão, a dependência econômica e a violência. Esse cenário tende a se agudizar em contextos de vulnerabilidade social, podendo dar um tom mais emblemático à velhice das mulheres.

A face do desprezo esconde o espectro da invisibilidade. As marcas da velhice imputam sobre a mulher idosa estigmas que lhe condenam à anulação social. Os cabelos brancos, os seios caídos, a pele flácida e enrugada formam a imagética diabolizada da mulher, que deve ser afastada dos olhos e do pensamento pelo horror e repugnância que causa no cerne de uma cultura narcisista em que se torna um imperativo a busca permanente pela perfeição dos corpos femininos.

Goldenberg (2015) refere em sua pesquisa realizada no Rio de Janeiro que as mulheres idosas não se sentem desprezadas pelos homens depois que elas envelheceram, elas simplesmente se sentem invisíveis porque sequer são notadas por eles quando andam nas ruas e já não recebem mais os olhares de antes, as cantadas, as piscadinhas, as viradas de pescoço, 
o que para a mulher brasileira, que se sente bem em ser paquerada, trata-se de um simbolismo de mortificação da sua feminilidade.

O destino da mulher idosa é o não-lugar. O não-lugar é o espaço que a mulher desse tempo geracional se conformou ao longo de toda a sua trajetória de vida em troca da segurança de ter uma casa, uma família, um sobrenome. Quando pensamos, especialmente, nas mulheres situadas em contextos locais remotos, de difícil acesso, e em condições de pobreza e vulnerabilidade social, entendemos que o casamento se constituía como a única alternativa de sobrevivência para elas, ou então, o exercício do trabalho braçal, penoso e desgastante. Assim, "é natural que [ela] seja tentada por essa facilidade, ainda mais porque os trabalhos femininos são muitas vezes ingratos e mal-remunerados; o casamento é uma carreira mais vantajosa do que muitas outras" (BEAUVOIR, 2016, p. 191).

Ao casar-se, as mulheres estariam livres da responsabilidade de prover a própria subsistência em troca da sujeição sexual a um homem mais velho que, pelo contrato do casamento, exercia uma relação de poder sobre a mulher que o autorizava, inclusive, a usá-lo pelas vias das várias formas de violência, o que, segundo Reed (2008), era uma forma de garantir a posse da mulher.

O casamento enquanto contrato sexual pressupunha o cumprimento de obrigações sociais ordenadas, segundo o que se esperava de um papel honrado pré-estabelecido para um homem e uma mulher. Assim, à mulher cabia o dever de gerar filhos, de não recusar-se sexualmente aos desejos de seu marido e os cuidados com a casa, enquanto ao homem, esperava-se que trabalhasse e fosse provedor. Dessa forma, a relação conjugal era destituída de um sentimento romântico, o que faz com que Del Priore $(2015$, p. 157) afirme que "um casamento preparado e refletido é tudo, menos paixão e sentimento. O corpo material não entra nesse tipo de raciocínio e muito difusamente surge a ideia de uma felicidade capaz de inundarlhe o ser".

As mulheres foram conformadas socialmente com essa sensação de segurança confundindo-a com a ideia de felicidade e realização na vida. Por mais que por detrás desse pseudo contentamento houvesse situações de violência, caberia às mulheres perdoarem os seus 
maridos, naturalizando o comportamento agressivo deles como inerente à masculinidade, coisa de homem. À mulher, caberia, portanto, uma conduta de perdão e paciência para não incitá-lo ainda mais à ira e ser responsável por agravar os episódios de descontrole do marido.

Nesse sentido, Pinsky (2017, p. 608-609) postula que:

\begin{abstract}
$\mathrm{Na}$ família-modelo dessa época, os homens tinham autoridade e poder sobre as mulheres e eram os responsáveis pelo sustento da esposa e dos filhos. A mulher ideal era definida a partir dos papeis femininos tradicionais - ocupações domésticas e o cuidado dos filhos e do marido - e das características próprias da feminilidade, como instinto materno, pureza, resignação e doçura. Ser mãe, esposa e dona de casa era considerado o destino natural das mulheres. Na ideologia dos Anos Dourados, maternidade, casamento e dedicação ao lar faziam parte da essência feminina; sem história, sem possibilidades de contestação. A vocação prioritária para a maternidade e a vida doméstica seriam marcas da feminilidade, enquanto a iniciativa, a força e o espírito de aventura definiriam a masculinidade.
\end{abstract}

O medo do abandono assombrava as mulheres e isso justificava a subserviência delas aos maridos. Ponce de Leão Nonato (2018) afirma que nem sempre essa subserviência garantia um casamento duradouro. A infidelidade dos maridos embriagava-os a ponto de descartarem as suas esposas quando eles achavam que elas tinham perdido os atrativos da juventude, por volta dos trinta e cinco aos quarenta anos de idade. Ao assumirem uma mulher mais jovem no lugar da ex-esposa, os homens velhos reafirmavam socialmente a masculinidade nos cânones da virilidade como forma de valorização social.

As mulheres abandonadas pelos maridos no momento da meia-idade eram lançadas à própria sorte junto aos seus filhos. Suas trajetórias de vida revelam a luta que travaram em duplas jornadas de trabalho exercidos dentro e fora de casa para que conseguissem dar conta de assumir integralmente a responsabilidade pela subsistência e os encargos da educação dos filhos. Assim, a abnegação de si em favor do dever de mãe tomou conta de grande parte da vida das mulheres idosas. A chegada da velhice inaugura a possibilidade de ruptura com a negação de si, uma vez que, desobrigadas dos deveres familiares, as mulheres encontrariam, finalmente, o momento oportuno para (re) encontrar-se consigo mesmas.

A gestão contemporânea da velhice, que iniciou desde a gerontologia e a criação dos centros de convivência para idosos, promove-se sob o signo do dinamismo. O idoso é elevado ao status de sujeito de direitos sendo incentivado a gozar de prerrogativas que, até então, eram 
vividas somente pelas pessoas mais jovens, como sair, namorar, viajar, fazer atividades físicas e frequentar espaços de socialização (LEÃO, 2015). A mulher idosa que, historicamente, tinha como destino social o papel de avó, passa a ter oportunidade de recriar-se em novos projetos de vida no âmbito da velhice ativa e bem-sucedida.

Os centros de convivência são espaços frequentados preponderantemente por mulheres em virtude do caráter das atividades oferecidas serem consideradas como típicas do público feminino, como dança, cursos de artesanato, palestras e oficinas e atividades físicas. Debert (1997) assinala que esses programas trabalham no sentido de propiciar a criação de uma outra identidade de velhice afinada com os valores da juventude atuando no sentido de oportunizar a realização de projetos que foram abandonados em outros momentos da vida. A dinâmica das atividades oferecidas nos centros de convivência para idosos se projetam no enaltecimento da autoestima provocando nas mulheres o desabrochar do feminino.

A velhice, então, se configura para as mulheres idosas como o momento de liberdade. Essa liberdade, contudo, só é possível se elas puderem contar com uma situação econômica que lhes garantam o provimento de suas necessidades básicas, como a aposentadoria ou a pensão do ex-marido, e, também, se elas dispuserem de uma boa condição de saúde capaz de lhes possibilitarem autonomia e independência. Nesse contexto, a mulher idosa sente que basta-se por si só. O papel de avó e/ou o de companheira afetiva de alguém é exercido de forma facultativa e em seus próprios termos.

Mas, essa liberdade alcançada pelas mulheres na velhice é estranha, como analisa Motta (1999). Para a autora, as idosas falam em liberdade de gênero como se esta se sobrepusesse à liberdade geracional, uma vez que elas podem até ter conseguido a liberdade como mulheres, de sair, circular e viver segundo a sua vontade, mas se elas conseguem fazer isso é porque permanecem inscritas no terreno da marginalidade geracional, pois são velhas e a velha já não importa porque não atrai mais os homens, não são consideradas bonitas e, por isso, não representam tanto ameaças ao poderio masculino.

A liberdade alcançada pelas mulheres na velhice permite a ressemantização do papel de gênero feminino, pois é o que lhes impulsiona a serem mais ativas para aproveitar esse momento 


\section{Revista \\ Debates Insubmissos}

da vida na tentativa de recomeçar de novo a viver, ao contrário dos homens que, na velhice, consideram que conquistaram somente a liberdade econômica com a chegada da aposentadoria, mas não se sentem livres em sua condição de gênero porque estão presos ao saudosismo do passado inviabilizado de ser vivido na velhice (PONCE DE LEÃO NONATO, 2018).

Os movimentos feministas na segunda metade do século $\mathrm{XX}$ trouxeram rebatimentos no formato da velhice feminina que ora se apresenta no tempo contemporâneo. Mas, se a própria velhice inaugura um tempo de liberdade na vida das mulheres, é também a velhice que questiona os limites dessa liberdade em um determinado estágio da existência.

Sendo o envelhecimento um processo contínuo durante todo o ciclo existencial, é normal que na velhice ele continue em curso, o que contribui para a aceleração do declínio das capacidades biofisiológicas e psicológicas, podendo, inclusive, levar o indivíduo à debilidade de suas funções e ocasionar dependência. A esse estágio da velhice dependente, Ribeiro (2008) chama de "senescência", que corresponde à decadência biológica responsável pelas transformações na aparência do indivíduo e também pelas alterações do funcionamento do corpo em virtude do envelhecimento.

As limitações da idade avançada levam as mulheres a repensarem o valor da liberdade, quando esta já não lhes cabe mais em sua autonomia e dependência. A finitude da vida inspira cuidados, requer segurança. A segurança consiste no amparo à velhice dependente em qualquer estágio que ela se apresente, seja a simples ajuda para tomar um remédio até a necessidade de cuidados intensivos em casos patológicos. Liberdade e segurança não são antinomias, são dois momentos vividos em alternância ao longo de todo o ciclo existencial.

Para Bauman e Dessal (2017), quem encontrar o equilíbrio entre liberdade e segurança, achará a felicidade. Mas, esse equilíbrio é inconciliável porque quanto mais "segurança" o indivíduo tem, significa perder um pouco de sua "liberdade" e a "liberdade" sem "segurança" é um completo caos. Portanto, há duas conclusões nesse dilema; a primeira, é que é impossível viver com as duas coisas juntas, e a segunda, é que segurança e liberdade são a mina de ouro que o ser humano sempre vai perseguir por toda a vida como fórmula de felicidade. Dessa forma, os autores apontam que 


\section{Revista \\ Debates Insubmissos}

É por isso que a civilização é um negócio, insiste Freud: para conseguir algo dela, os seres humanos têm de renunciar a outra coisa. Tanto os bens obtidos quanto os cedidos em troca são valorizados e desejados com fervor; por isso, cada sucessiva fórmula de intercâmbio não é mais que um arranjo passageiro, o produto de uma transação nunca plenamente satisfatória para nenhuma das partes desse antagonismo que arde sem chama, perpetuamente. A discórdia amainaria se fosse possível atender ao mesmo tempo aos desejos individuais e às demandas sociais. Mas, isso não ocorrerá. Para alcançar uma vida satisfatória - ou suportável, vivível, para sermos mais exatos -, são tão imprescindíveis as liberdades de agir segundo os próprios impulsos, urgências, inclinações e desejos quanto as restrições impostas no interesse da segurança, já que segurança sem liberdade equivaleria à escravidão ao passo que liberdade sem segurança desataria o caos, a desorientação e uma perpétua incerteza, redundando em impotência para agir de forma resoluta. Mas, ambas são e continuarão a ser para sempre inconciliáveis (IDEM, p. 16-17).

A bandeira de luta do movimento feminista sempre foi a favor da liberdade das mulheres. Mas, a liberdade de gênero precisa ser ponderada no contexto geracional, especialmente quando as mulheres alcançam a velhice. As mulheres idosas que assumem a liberdade de gênero sofrem com os estigmas da "velha assanhada", "depravada" e "asquerosa". Por conta disso, elas temem padecer o resto da vida na solidão. Por isso, liberdade e segurança são questões que não podem ser pensadas em paralelo, pois qualquer uma das duas assumidas isoladamente implicariam na incompletude do ser.

Bauman e Dessal (2017, p. 29) acrescentam, nesse sentido, que o excesso de liberdade que a modernidade líquida trouxe provocou nos indivíduos a necessidade de segurança, pois "a fonte do sofrimento parece ser agora a carência de segurança, que envenena o gozo de uma liberdade individual sem precedentes". Ao contrário dos homens que sempre gozaram de liberdade, mas que, na velhice, sentem que ela foi cerceada pela saída do espaço público, as mulheres, em uma determinada altura da existência, fadigam-se do pouco tempo de liberdade conseguida na velhice após sentirem que exauriram o sentido de recuperação do tempo perdido.

As alternativas de segurança procuradas pelas mulheres vai depender da forma como elas percebem a sua condição feminina no mundo. Gênero é uma construção social tecida no âmbito das relações de poder entre os sexos (SCOTT, 1991). Enquanto construção social aprendida, sofre influência de vários determinantes, como raça e classe social. As mulheres idosas que afiançaram a sua segurança na instituição do casamento, provavelmente sintam-se seguras ao lado de um companheiro. Por outro lado, as mulheres que conseguiram alçar um 


\section{Revista \\ Debates Insubmissos}

estatuto de independência maior ao longo da vida, provavelmente, redimensionem o sentido da segurança para outros escapes que não, necessariamente, seja um companheiro.

Na pesquisa de Goldenberg (2014), as mulheres idosas revelam que se sentem seguras com o apoio das amigas. São as amigas que lhes visitam nos hospitais quando elas precisam ser internadas, bem como são elas que prestam os cuidados necessários para a reabilitação de suas saúdes. O apoio das amigas é suficiente a ponto de elas dispensarem a dedicação dos filhos adultos como uma forma de não querer atrapalhá-los em suas rotinas. Essas mulheres idosas moram, geralmente, sozinhas e se sentem muito bem com a independência, mesmo estando em idade avançada. Elas vão aos cinemas, teatros e viajam com as amigas, sendo estas, então, os seus portos seguros na maior parte do tempo.

Por outro lado, na pesquisa de Ponce de Leão Nonato (2018), as mulheres idosas preferem negociar a liberdade em troca da segurança de terem um companheiro aos seus lados. Para isso, elas se sujeitam a mudar a forma de se vestir, a abrir mão de suas amigas e a não mais frequentar lugares transgressores, como os centros de convivência para idosos, já que, lá, é, muitas vezes, considerado um ponto de encontro de pessoas solteiras e disponíveis para relacionamentos afetivo-sexuais. Para essas mulheres, a figura masculina será sempre um porto de proteção.

As mulheres que, durante toda a sua trajetória de vida, dedicaram-se a cuidar dos outros e que, no início da velhice, gozaram da liberdade de gênero, em uma determinada altura de sua existência, passam a não se sentirem realmente livres pelo fato de não terem uma companhia masculina ao seu lado. Sentem-se livres, mas não se sentem seguras. A consciência do fim da vida leva a repensar a negociação da liberdade em troca da segurança de ter um homem ao seu lado e essa escolha pode implicar na reificação das relações de dominação que por todo o curso de suas vidas lhes subalternizaram.

Estar-junto é uma dimensão de realização da sexualidade das mulheres idosas. O tensionamento liberdade-segurança também reflete na forma como elas vivem a sexualidade durante o curso da velhice, que está diretamente relacionada à ressignificação do feminino. A 
nova gestão da velhice impulsionou a sexualidade das mulheres. Por meio da sexualidade, as mulheres idosas buscam o gozo de sentirem-se vivas.

\section{MULHERES IDOSAS E A REALIZAÇÃO DA SEXUALIDADE}

Ao longo da história, a sexualidade feminina vem sendo vigiada e reprimida nos moldes do patriarcado. Desde a tenra idade, as mulheres foram educadas a se manterem virgens até o casamento enquanto aos homens sempre foi não só permitida, mas, fundamentalmente, incentivada a liberdade sexual como forma de testificação da masculinidade, que só poderia ser validada no primado da heterossexualidade.

No escopo machista, criou-se uma dualidade entre as mulheres para categorizá-las entre aquelas que servem exclusivamente para o divertimento sexual e, por isso, são moralmente desvalorizadas, e as conservadoras, que servem para casar e viver uma vida socialmente honrada. Essa categorização se fundamenta exclusivamente no senso patriarcal de moralidade, já que se considera que toda mulher é portadora de uma natureza santificada e pecaminosa ao mesmo tempo, pois o corpo feminino "não deixou de ter "tensões" entre o bem - procriação, virgindade de "Maria", castidade e cuidado com a família - e o mal, sexualidade, prostituição, luxúria e perversão da alma [...]" (ROIZ, 2009, p. 408).

O prazer sexual feminino sempre foi negado, pois era considerado coisa de prostituta. Dentro do casamento, a realização da sexualidade feminina era um dever da mulher para agradar os desejos do marido e tinha como fim último a reprodução. Nesse sentido, Reed (2008, p. 152) afirma que "é evidente que o casamento não foi introduzido para satisfazer as exigências humanas normais de afeto sexual e companhia e menos ainda para a mulher. $\mathrm{O}$ casamento foi estabelecido aberto e declaradamente para servir aos interesses dos homens [...]".

A prática do sexo dentro do casamento era, portanto, uma obrigação da mulher ao marido. Por ser caracterizado como um dever da mulher e um direito do marido, nem sempre as relações sexuais eram realizadas de forma consensual. Admitimos que relações sexuais forçadas se configuram como estupros e isso era muito comum em virtude da recusa sexual da 


\section{Revista \\ Debates Insubmissos}

mulher, que poderia acontecer motivada por uma simples indisposição biológica e/ou até mesmo afetiva.

Para Ponce de Leão Nonato (2018), o homem casava-se no intuito de afirmar-se socialmente como alguém independente e honrado. A esposa deveria suplantar o lugar subserviente da mãe com o adicional da permissão sexual. Para o marido, o prazer sexual da esposa era neutralizado pelo instinto materno. Assim, o sexo não deveria ser uma atividade prazerosa para ela, mas tão-somente para ele. A performance da atividade sexual no âmbito do casamento era despida de carícias afetivas e encarada como uma forma de descarga sexual do homem que seria aliviada no ato da ejaculação. Quando o homem procurava investimentos maiores em seu prazer, recorria às mulheres fáceis que permitiam uma prática sexual mais completa e abrangente, não apenas o coito vaginal.

Dessa forma, ao longo de toda a vida a mulher casada foi classificada no espectro de santidade em que o exercício da sexualidade era apenas uma atividade-fim para a reprodução e uma obrigação conjugal e não uma fonte de prazer e realização pessoal. Por conta da experiência sexual mal-sucedida durante a vida, as mulheres idosas podem abandonar a sexualidade na velhice e, inclusive, a atividade sexual por não terem cultivado a auto-estima, pelos traumas advindos das experiências violentadoras para a prática do sexo e/ou por terem perdido o desejo sexual.

As mudanças biofisiológicas que se processam no corpo feminino após a chegada da menopausa, como o estreitamento da vagina, a lentidão da lubrificação vaginal (PASCUAL, 2002) e as alterações hormonais podem contribuir para arrefecer o desejo e causar incômodos na penetração vaginal. Mas, isso não impede as mulheres de continuarem fazendo sexo e/ou de expressarem a sua sexualidade quando atingem à velhice. Os impedimentos à realização da sexualidade feminina estão mais ligados a razões de ordem subjetiva e moral do que às limitações do próprio corpo envelhecido.

Os tabus em torno da sexualidade feminina na velhice dão conta de aprofundar a depreciação moral da mulher, pois parte-se do pressuposto de que se ela não pode mais gerar filhos, está, portanto, dispensada da atividade sexual e de qualquer outra manifestação ligada à 
expressão da sexualidade. Do contrário, a mulher idosa sofrerá com a censura da ridicularização e do desprezo. É o que vemos no conto "Mas vai chover", de Clarice Lispector (1998), que ilustra o drama da personagem Angélica, uma mulher idosa que busca nos braços de um homem mais jovem a satisfação de seus desejos sexuais. Porém, quando ela não consegue mais atender às suas exigências bilionárias, ele a abandona de forma vil, derramando, antes, a cólera de sua repulsa ao chamá-la de velha sem vergonha, desgraçada, porca e vagabunda.

A escolha da mulher em manter a vivência de sua sexualidade na velhice é um ato transgressor contra a ditadura do corpo e o machismo. Os esforços envidados para a criação do Viagra e outros estimulantes sexuais se empenharam em reativar a potência sexual de homens que apresentavam disfunção erétil, o que resultou em abandonos de casamentos com mulheres idosas para a busca de parceiras sexuais mais jovens (BRIGEIRO e MAKSUD, 2009) em consequência da reativação imediata da virilidade, o que tornou possível a reconquista da valorização social da masculinidade de homens idosos. Às mulheres idosas, restava a paciência em esperar que os velhos maridos senis ${ }^{2}$ retornassem ao lar para receberem os seus cuidados até o fim da vida.

No tempo contemporâneo, as mulheres idosas tem assumido um protagonismo diferente em relação à sua sexualidade. Devemos os créditos dessa mudança comportamental à nova gestão de velhice promovida pelos programas de terceira idade. Nos centros de convivência para idosos, as mulheres idosas são estimuladas a priorizarem os próprios interesses deixando de lado o comportamento passivo que as anularam ao longo de toda a vida. É assim que elas retomam a vontade de se arrumarem e o prazer de socializar com outras pessoas fora do seu círculo familiar, o que representa a oportunidade de reativação da sexualidade. Debert (1997) assinala que os programas voltados para a terceira idade atuam no sentido de propiciar a criação de uma outra identidade de velhice afinada com os valores sociais da juventude, pois oportuniza a realização de projetos que foram abandonados em outros momentos da vida.

\footnotetext{
2 Para Ribeiro (2008), a senilidade é quando o processo de envelhecimento vem acompanhado de doenças incapacitantes que comprometem o envelhecimento saudável.
} 


\section{Revista \\ Debates Insubmissos}

Nos centros de convivência para idosos, as mulheres se sentem à vontade para partilharem os dramas de suas vidas com outras mulheres que se encontram na mesma condição geracional e que possuem vivências parecidas. A identificação de interesses em comum se constitui como um mecanismo desinibidor para dar vazão às curiosidades que elas tem sobre sexo e a sexualidade. A partir das experiências sexuais satisfatórias vivenciadas pelas outras colegas, a curiosidade é estimulada e elas são encorajadas a experimentarem sem o peso da culpa e da vergonha o prazer sexual na sua idade. Esses núcleos de sociabilidade inauguram, assim, um divisor de águas na vida das mulheres idosas, que passam a encarar a velhice como um tempo de investimento em si depois de tantos anos dedicados ao casamento e à educação dos filhos.

Nem todas as mulheres idosas estão dispostas a retomarem a prática da atividade sexual, mesmo aquelas que frequentam os programas de terceira idade. Isso vai depender da forma como cada mulher elabora a sua existência nesse momento do ciclo de vida a partir das experiências pretéritas. A renúncia da atividade sexual não impede as mulheres de viverem a sua sexualidade sob outras formas de expressão, de igual forma prazerosas e autorrealizadoras, pois, para Ribeiro (2005, p. 124-125),

Sexualidade é a maneira como uma pessoa expressa seu sexo. É como a mulher vivencia e expressa o "ser mulher" e o homem o "ser homem". Expressa-se através dos gestos, da postura, da fala, do andar, da voz, das roupas, dos enfeites, do perfume, enfim, de cada detalhe do indivíduo.

Confunde-se muito sexualidade com relação sexual. A relação sexual é um componente da sexualidade e ao contrário do que muita gente pensa não é apenas a relação pênis-vagina, mas sim, a troca de sons, cheiros, olhares, toques, secreções e carícias.

A expressão da corporeidade que se perfaz como resultante do prazer de se arrumar e chamar a atenção por onde passa é uma manifestação da sexualidade importante para a mulher idosa afirmar-se dentro de sua condição de sujeito sexuado que por durante muito tempo foi esquecida pela baixa autoestima decorrente da desvalorização do seu corpo velho. O fato de ela não se envolver de forma afetivo-sexual com outra pessoa trata-se de uma escolha deliberada pela priorização de eleger-se como sua principal fonte de realização pessoal.

As mulheres que, por sua vez, optaram por manter a atividade sexual na velhice buscam, nesse momento da vida, o próprio prazer em primeiro lugar, uma vez que sempre foram 
anuladas em favor da satisfação sexual de seus companheiros. Na velhice, elas querem gozar. E esse gozo não é apenas físico, mas, fundamentalmente, um gozo almático, um estado de plenitude alcançado pelo ser quando elas se sentem contempladas em suas fantasias românticosexuais, de se sentirem desejadas e acariciadas nas preliminares do sexo, o que até então não conheciam pela forma como os seus antigos companheiros conduziam a performance sexual, cuja única preocupação deles era chegar à ejaculação.

Nesse sentido, Bozon (2004, p. 65) afirma que a sexualidade genital nas últimas décadas do século XX recebeu investimentos que prolongou o sexo em comparação à forma tradicional de reduzi-lo unicamente à genitalidade. Assim,

[...] para cada indivíduo em particular, a transição para a sexualidade genital, que tradicionalmente poderia ser feita sem uma verdadeira preparação, estendeu-se: existe hoje um modelo de exploração física e relacional por etapas, beijos profundos, carícias corporais, carícias genitais e, finalmente, penetração genital. De agora em diante, o processo se realiza durante vários anos e, cada vez menos, com o mesmo parceiro [...].

Essa concepção mais rebuscada da sexualidade surge quando a procriação não assume mais lugar central na atividade sexual, levando o indivíduo a buscar outras formas de realização no plano da intimidade e da afetividade. As próprias mudanças biofisiológicas retardam as respostas do corpo para chegar à lubrificação vaginal. Por conta disso, é necessário um investimento maior nas condições de excitação para que o corpo ative as funções que ordenem o coito. As carícias sexuais prolongam o ato sexual tornando-o mais satisfatório na velhice à medida que propicia aos sujeitos um conhecimento mais profundo do próprio corpo e do corpo do outro. Se na juventude e maturidade, o objetivo principal do sexo privilegiava a genitalidade, na velhice, a o coito só é possível se todo o corpo for doado em benefício da excitação.

Embora a frequência da atividade sexual das mulheres tenha diminuído na velhice em virtude de nem sempre elas conviverem com os novos companheiros, a satisfação com a vida sexual tem sido maior do que no período em que elas viviam com os seus ex-maridos. No momento do ato sexual com o marido, as mulheres não tinham ação ou quando tinham, estavam limitadas a agirem dentro dos comandos do marido para dar prazer a ele.

O novo ato sexual na velhice permite que elas tenham uma liberdade maior para participar da relação de modo a dar e receber prazer por meio das carícias sexuais. A obtenção 
do próprio prazer não é uma preocupação egoísta, ao contrário, é interrelacional com o parceiro à medida que é por meio da sensação de ser desejada que a mulher idosa consegue se envolver sexualmente e produzir as condições para a excitação que permitam a consumação do ato sexual. A mulher "atrai e excita-se quando se sente desejada, quando se depara com um homem que a faz sentir-se mulher. [...] é extremamente importante para a mulher sentir-se atraente, gostar de si, achar-se bonita, conhecedora de seu corpo e de suas reações, para que se solte e se proponha a entrar em sintonia, a atrair" (RIBEIRO, 2005, p. 126).

A reciprocidade na relação sexual é o fator que anula a posição da mulher como mero objeto sexual. O envolvimento sexual da mulher na velhice não acontece puramente no ato sexual. Para Gagnon (2006, p. 123), a conduta sexual não é uma questão simples de determinação biológica, "ao contrário, a ênfase recai sobre os processos psicossociais e as situações histórico-culturais que dão sentido ao comportamento e permitem a integração e a reorganização das informações e habilidades aprendidas em outras etapas do ciclo de vida". Os roteiros (fantasias) que acionam a conduta sexual na mulher tem a ver com a forma como ela elabora as tramas de romance que lhe despertou sexualmente na adolescência na expectativa de viver um grande amor com o príncipe encantado que lhe realizaria em todas as dimensões de sua vida.

Gagnon (2006) explicita, ainda, que os roteiros são montados e desmontados adaptandose às circunstâncias de cada ciclo da vida. A conduta sexual evoca respostas aprendidas em situações concretas no passado e se modelam de forma flexível e cambiante às particularidades sociohistóricas que se circunscrevem no tempo presente provocando as condições para a adaptação humana, sobretudo quando o indivíduo apresenta algum tipo de disfunção sexual. O passado é, então, um recurso que pode ser editado, reescrito e sobre ele aplicado novas adaptações que o moldem às circunstâncias atuais.

A velhice, então, se transforma em um momento do ciclo existencial da mulher capaz de devolver-lhe a virgindade sexual. Estamos falando de uma virgindade não himenal, e sim, uma virgindade simbólica, ligada à descoberta e experimentação prazerosa de uma nova sexualidade até então desconhecida pelas mulheres idosas (PONCE DE LEÃO NONATO, 


\title{
neviste

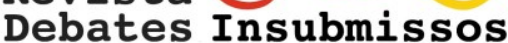

2018). Trata-se, assim, de uma jovialidade de espírito diretamente ligada à liberdade de poder ser o que elas querem ser e não mais o que os outros determinaram para o seu destino.

A chegada da velhice é, então, o marco de despertamento do feminino adormecido pela obrigação da responsabilidade. A percepção dessas mulheres enquanto sujeitos de suas próprias histórias ocorre no marco temporal da velhice, em que o único compromisso assumido passa a ser com elas mesmas, já que estão dispensadas da obrigatoriedade dos cuidados com os filhos. Os papeis sociais assumidos por essas mulheres ao longo de suas vidas lhes destituíram de si próprias em favor de algo e/ou de alguém. A velhice é, assim, o período do ciclo existencial em que as mulheres conseguem recuperar a sua individualidade interrompida no interstício do tempo.

Beauvoir (2016, p. 387; 388) elucida essa questão afirmando que,

\begin{abstract}
Como a moça que sonha com que será seu futuro, ela evoca o que poderia ter sido o seu passado. [...] Essa personalidade que acaba de descobrir por contraste com a mesquinhez de seu destino, ela a exibe, louva-lhe os méritos, reclama imperiosamente que lhe façam justiça. Amadurecida pela experiência, pensa que é capaz enfim de se valorizar; gostaria de recomeçar. Antes de tudo, procura deter o tempo num esforço patético. [...] Declaram todas que nunca se sentiram tão jovens. Querem persuadir os outros que a passagem do tempo não as atingiu efetivamente, põem-se a "vestir-se como jovens", adotam mímicas infantis. A mulher que envelhece sabe muito bem que se deixa de ser um objeto erótico não é somente porque sua carne não oferece mais ao homem riquezas frescas: é também porque seu passado, sua experiência fazem dela, queira ou não uma pessoa; lutou, amou, quis, sofreu, gozou por sua conta: esta autonomia a intimida; procura renegá-la; exagera sua feminilidade, enfeita-se, perfuma-se, faz-se toda encanto, graça, pura imanência; admira com olhar ingênuo e entonações infantis o interlocutor masculino, evoca com volubilidade suas recordações de menina: ao invés de falar, cacareja, bate palmas, ri às gargalhadas. É com uma espécie de sinceridade que representa essa comédia. Pois o interesse novo que dedica a si mesma, o desejo de se arrancar às antigas rotinas e de partir novamente dão-lhe a impressão de que recomeça.
\end{abstract}

A impressão do recomeço reveste o sentido da existência da mulher na velhice. A velhice é o momento da vida privilegiado para a recuperação do tempo em que essas mulheres se anularam. Por mais que não consigam reescrever uma história diferente da que elas tiveram no passado, a liberdade lograda nessa altura do ciclo existencial permite a reparação de si próprias, “[...] a compensar simbolicamente os erros e fracassos do passado" (BEAUVOIR, 2016, p. 388). 


\section{Revista \\ Debates Insubmissos}

Por meio da sexualidade, a idosa reescreve a sua história de mulher e, assim, elas provam para o machismo que mulher não tem prazo de validade, que mulher é mulher a vida inteira, pois a feminilidade não depende de provas viris, como a masculinidade patriarcal, que condiciona o estatuto de ser homem dentro de um período em que vigora a potência sexual, o que está circunscrito no limite do tempo, pois o patriarcado esqueceu de considerar a velhice como ameaça à sustentação da masculinidade (BOURDIEU, 2016).

Ponce de Leão Nonato (2018) refere que o sexo assume lugar de centralidade na vida dos homens, por isso, quando eles atingem à velhice, não conseguem se sentir velhos até o momento em que apresentam debilidades em suas funções orgânicas que os impedem de continuar exercendo a atividade sexual. Quando esse momento chega, eles sentem o decreto da velhice imposto, por isso, se sentem inúteis como homens e, assim, pedem para que a morte lhes sobrevenham. As mulheres, não. Como a atividade sexual nunca assumiu lugar de centralidade em suas vidas, elas sempre conseguem se reinventar dentro de sua condição feminina. Quando o desejo sexual cessar ou quando a atividade sexual não lhes parecer mais oportuna, elas continuarão sentindo prazer em gozar da liberdade de poder sair sem compromisso, de se arrumar, dançar e conversar com as amigas. Dessa maneira, as mulheres conseguem viver a sexualidade até o fim da vida.

Nas mais diversas formas de expressão da sexualidade da mulher na velhice, o que elas buscam é liberdade, inclusive em seus relacionamentos afetivo-sexuais. Por isso, as mulheres idosas são sexualmente atraídas pelos homens mais jovens porque sabem que os homens de sua idade buscam nelas uma cuidadora de suas debilidades. Embora elas ainda tenham fantasias romântico-sexuais, elas não fazem questão de um novo arranjo matrimonial com um novo companheiro.

A preferência pelos homens mais jovens se dá não só em razão do vigor sexual, mas pelo fato de eles conseguirem reanimar nelas a potência romântica adormecida no tempo, o que lhes colocam em situação equiparada de valorização sexual com a mulher mais jovem. Nesse sentido, Sheehy (2008, p. 176) chama a atenção para o fato de que, 


\title{
Revista \\ Debates Insubmissos
}

\begin{abstract}
Sentir atração sexual por homens mais jovens é apenas uma fase do Renascimento Romântico. Ela pode levar a um romance transformador ou pode cumprir seu ciclo em fantasias e em alguns flertes. Se ajudar a superar a inevitável crise de vaidade que se abate sobre quase todas as mulheres, já terá cumprido um objetivo.
\end{abstract}

Assim como acontece com os homens em seus relacionamentos com mulheres mais jovens, o interesse dos homens jovens pelas mulheres idosas não deixa de estar circunscrito dentro de uma relação negociada, especialmente em contextos de pobreza e vulnerabilidade social em que a mulher idosa se constitui como uma segurança em razão de sua condição econômica. Como se trata de relacionamentos não-duradouros, a condição de sua vigência é o grau de satisfação de ambas as partes com a relação.

Esse modelo de relacionamento, Giddens (1993, p. 68-69) denomina de "relacionamento puro", derivado das mudanças produzidas no campo da sexualidade contemporânea que transformam a ideia de amor romântico em um vínculo que perdura enquanto os indivíduos lograrem satisfação com a relação. De acordo com este autor,

Refere-se a uma situação em que se entra em uma relação social apenas pela própria relação, pelo que pode ser derivado por cada pessoa da manutenção de uma associação com outra, e que só continua enquanto ambas as partes considerarem que extraem dela satisfações suficientes para cada uma individualmente, para nela permanecerem. Para a maior parte da população sexualmente 'normal', o amor costumava ser vinculado à sexualidade pelo casamento, mas, agora, os dois estão cada vez mais vinculados através do relacionamento puro. [...] o relacionamento puro é parte de uma reestruturação genérica da intimidade.

Embora homens e mulheres idosos adotem esse tipo de vínculo em seus relacionamentos afetivo-sexuais, as mulheres sempre serão mais censuradas por isso do que os homens, uma vez que a liberdade sexual é socialmente esperada para o sexo masculino e não para as mulheres, mesmo elas sendo economicamente independentes e desimpedidas civilmente.

A decisão das mulheres idosas de continuarem vivendo a sua sexualidade é um ato transgressor, pois implica a priorização de si em um mundo onde a mulher ainda é vista de forma subalternizada e passiva. A teoria feminista precisa lançar o olhar sobre as formas de luta que as mulheres empreendem para se ressignificar dentro do momento existencial da velhice, pois a história de cada mulher não finda ao término do seu período produtivo e reprodutivo. É no escopo da liberdade que elas conseguem se reinventar e escrever a sua história de forma emancipada até o fim da vida. 


\section{METODOLOGIA}

A pesquisa foi empreendida a partir do olhar dialógico proposto por Edgar Morin (2012) para quem o conhecimento é tecido junto entre diferentes disciplinas em uma rede de conversação mútua e articulada. Assim, as fontes de discussão deste trabalho orientam-se em uma perspectiva interdisciplinar tecida entre a filosofia, a antropologia e a sociologia. A orientação metodológica caminha nos rumos da fenomenologia (MERLEAU-PONTY, 1999), pois oferece o aporte necessário para a compreensão que o sujeito faz de sua trajetória existencial e de seu contexto vivencial. Trata-se de uma pesquisa qualitativa realizada na cidade de Parintins, Amazonas, no período de 2014 a 2018, por meio de formulários de entrevistas aplicados a vinte mulheres idosas sexualmente ativas e heterossexuais. Para preservar a identidade das mulheres, elas serão nomeadas por pedras preciosas.

\section{ANÁLISE DO CAMPO DA PESQUISA}

No contexto histórico da década de 1930 a 1950 do século XX, a sexualidade feminina ainda trazia os resquícios do século XIX consolidados na educação transmitida pelos pais dessas mulheres, que primava por valores como virgindade, submissão e procriação. Esses traços se delineavam em contornos particulares mais ou menos acentuados conforme os lugares em que eram estabelecidos, podendo variar um pouco entre cidades grandes e menores, diferentes grupos ou classes sociais (PINSKY, 2017).

Nesse período, as mulheres que nasceram nas comunidades rurais do baixo Amazonas experimentaram a adolescência trabalhando no roçado e na extração da juta com os seus pais para contribuir no sustento da família. Como o acesso aos estudos era difícultado em razão da falta de escolas no interior e pelas condições de vida de sua família que não permitiam enviarlhes para estudar fora de seus locais de origem, o casamento se apresentava como o único passaporte capaz de pôr fim à vida difícil que elas tinham "porque nós trabalhávamos muito. Trabalhávamos mesmo como se fosse um homem. Nós, mulheres, fazíamos trabalho de um homem, fazendo cerca, carregando pau, limpávamos o campo" (Jasmin, 90 anos, entrevista, 2018). Ao casar-se, ela estaria livre da responsabilidade de prover a própria subsistência não 
precisando mais submeter-se à execução desses trabalhos árduos que ficariam a cargo do seu marido, devendo-lhe em troca a obrigação de exercer a sua vocação natural de ser dona de casa, esposa e mãe.

O casamento definiria o destino da mulher na vida ao liberá-la da autoridade do pai para ser assumida pelo marido que lhe conferiria existência civil mediante o estatuto de mulher casada. Enquanto não era casada, a mulher não existia socialmente. Ela não tinha direito de fazer as próprias escolhas, incluindo decidir por qual pretendente gostaria de se casar. Quem tomava as decisões por ela era a figura paterna ou a mãe, na ausência do pai. Sendo assim, o casamento era um contrato entre homens sobre o destino da mulher. De acordo com Pateman (1993, p. 236),

As mulheres foram forçadas a participar desse suposto contrato. Os costumes sociais destituíram as mulheres da oportunidade de ganharem o seu próprio sustento, de modo que o casamento era a sua única chance para elas terem uma vida decente. O contrato de casamento era exatamente como o contrato em que os senhores de escravo das Índias Ocidentais impunham a seus escravos; o casamento não era nada mais do que a lei do mais forte, aplicada pelos homens em detrimento dos interesses das mulheres, mais fracas.

Quando as coisas caminhavam conforme o que estava proposto, as mulheres entendiam que tinham um bom casamento e que o marido lhes tratavam bem, apesar de muitas vezes sofrerem maus-tratos físicos em decorrência do abuso de poder proveniente do excesso de liberdade que eles tinham que lhes permitiam fazer o que quisessem de suas vidas sem dever satisfação dos seus atos, como acontecia quando eles bebiam ou então quando tinham casos extraconjugais. Hortência (67 anos) revela que "ele era ruim, mas ele era bom para outras coisas. Assim, dizer que ele me maltratava, de passar mal, de comedoria, de bebida, isso eu não tenho o que me queixar dele. Agora, a ruindade dele era me bater" (entrevista, 2018).

A violação da integridade física era compensada pela proteção que o marido oferecia em prover as necessidades de subsistência. Como dele dependia o seu sustento, à mulher caberia uma conduta de perdão e paciência para não incitar-lhe ainda mais a ira e não ser responsável por agravar as consequências dos episódios de descontrole ocasionados pela agressividade do marido, cuja conduta era compreensível por entender que fazia parte da natureza masculina. Hortência (67 anos) refere que tinha uma vida feliz não por ser respeitada e valorizada pelo 
marido, mas por não lhe faltar nada como havia sido prometido ao se casar. Assim, "[...] os motivos do casamento continuavam a passar longe do coração” (DEL PRIORE, 2015, p. 156). Esse contentamento velado que escondia as marcas de sofrimento da violência silenciou as mulheres por longo tempo no âmbito da vida social.

Rosa (72 anos) decidiu romper o silêncio que lhe atormentava por não questionar as atitudes levianas do marido, chegando ao estopim quando ele the propôs "fazer um filho em uma mulher e trazer pra ti (sic!) criar como tu criaste os teus filhos" (entrevista, 2018). A indignação que ela sentiu após ouvir a proposta lhe enfureceu a ponto de sair correndo atrás do marido em torno da mesa da cozinha com uma faca que ela estava utilizando no momento para tratar peixe, na intenção de matá-lo.

A separação do casal foi procurada pelo marido que se sentiu ofendido após essa atitude da esposa. A atitude transgressora de Rosa (72 anos) representou um grito de imposição frente aos desmandos do marido que passou dos limites em lhe desmoralizar enquanto sua mulher depois de quase trinta anos de dedicação e obediência dela seguindo os cânones morais do que se esperava de uma mulher casada. Assim, ela relata:

Durante o tempo em que eu vivi com ele foi muito bom. Eu não sei se era bom porque eu nunca dei motivo, talvez. Eu ia tudo pelo que ele queria, ele mandava e desmandava em mim, por isso que eu tinha uma vida que o pessoal todo admirava. Quando eu me separei dele, que os outros não sabiam de nada, diziam: Meu Deus! Por que ela se separou dele? Era uma família parece que perfeita e do dia pra noite parece que não deu mais certo (ENTREVISTA, 2018).

A submissão da mulher ao marido para satisfazer as vontades dele implicava na violação de si mesma, ainda que fosse justificada como prova de seu amor e de sua fidelidade pela gratidão que ela lhe devia em troca da proteção que ele lhe oferecia.

As mulheres velhas de Parintins descobriram a sexualidade somente quando se casaram, momento em que foram expropriadas do direito de explorarem os prazeres do próprio corpo em nome da vontade do marido que lhes ensinou de forma violenta, submissa e bestializada que a vida sexual se diluía na genitalidade com a finalidade exclusiva de dar prazer ao homem e de gerar filhos, sendo uma obrigação da mulher à qual ela deveria tratar de forma fria e contida sob o risco de lhe ser atribuído o estigma de prostituta. Assim diz Tulipa (64 anos): 


\section{Revista \\ Debates Insubmissos}

Eu me sentia um pouco bem e um pouco mal porque eu não gostava, assim, dele. Eu aceitava porque ele era meu marido, mas não era do meu gosto, não. Eu me negava pra ele porque eu não queria mesmo. Ele era sempre mal. Quando ele queria, ele fazia um carinho. Mas, aquele carinho de mal, não era assim um carinho que ele me acarinhasse, né, e eu nunca acarinhei ele por isso. Ele era muito violento. Ele me batia, puxava pelo cabelo, jogava a faca atrás de mim e eu corria. Ele fazia à força (ENTREVISTA, 2018).

Quando Tulipa (64 anos) revela que se sentia um pouco bem durante a relação sexual, ela se refere ao prazer genital que sentia pela estimulação clitoriana provocada pela penetração sexual. O "carinho do mal" que ela diz que o marido fazia consistia na masturbação para propiciar a lubrificação vaginal enquanto o pênis dele ganhava ereção para consumar o coito. O fato de ela se sentir mal demonstra que o prazer sexual não atingia a completude do seu ser, pois o que acontecia era, apenas, um prazer localizado e momentâneo, desprovido de um "carinho que lhe acarinhasse", ou seja, que lhe tocasse a alma pelo fato de ela se sentir amada e desejada por um homem.

Embora a frequência da atividade sexual das mulheres tenha diminuído na velhice em virtude de elas não conviverem com os seus namorados, a satisfação com a vida sexual tem sido maior do que no período em que elas viviam com os seus ex-maridos. Se antes, o ato sexual "era pega, pega, vai pra cá, faz, hoje, é diferente. Eu abraço o cara, beijo o cara, cheiro o cara. Hoje, é melhor" (Rosa, 72 anos, entrevista, 2018). No momento do ato sexual com o marido, as mulheres não tinham ação ou quando tinham, estavam limitadas a agirem dentro dos comandos do marido para dar prazer a ele. O novo ato sexual na velhice permite que elas tenham uma liberdade maior para participar da relação de modo a dar e receber prazer por meio das carícias sexuais. A obtenção do próprio prazer não é uma preocupação egoísta, ao contrário, é interrelacional com o parceiro à medida que é por meio da sensação de ser desejada que a mulher velha consegue se envolver sexualmente e produzir as condições para a excitação que permitam a consumação do ato sexual. A mulher "atrai e excita-se quando se sente desejada, quando se depara com um homem que a faz sentir-se mulher. [...] é extremamente importante para a mulher sentir-se atraente, gostar de si, achar-se bonita, conhecedora de seu corpo e de suas reações, para que se solte e se proponha a entrar em sintonia, a atrair" (RIBEIRO, 2005, p. 126). 


\section{Revista \\ Debates Insubmissos}

A construção do prazer sexual na mulher velha se inicia no momento em que ela se sente capaz de atrair sexualmente alguém que lhe corresponda. Sendo assim, a velha não se propõe ao ato sexual de forma impulsiva, como por um elogio que recebe, mas quando sente que o parceiro foi atraído pela sua capacidade de sedução. Na consumação do ato sexual, o seu envolvimento acontece mediante as carícias que lhe estimulam a excitação e pela autorização do parceiro em deixar que ela também lhe corresponda. Esse entrelaçamento do desejo cria as condições de intimidade que produzem afetividade entre o casal, como ilustra Hortência (67 anos),

Eu gosto dele, estamos nos gostando, aí a gente vai fazer aquela relação, então eu vou pegando amizade nele, aí a gente vai, vai, vai criando amizade. A pessoa vem, abraça e carinha, beija, aquilo dá vontade porque o cara não vai logo na marra. Tem que fazer um carinho para poder a gente também ter um carinho com ele porque se a gente não tiver um amor, um carinho naquela pessoa, a gente vai ter relação como? Se não faz aquele carinho, não tem gosto (ENTREVISTA, 2018).

Hortência (67 anos) mostra que é a forma como o ato sexual se processa que produz o envolvimento afetivo entre os parceiros, e não antes, a partir de uma relação contratual que pode estabelecer uma relação sexual prazerosa e culminar em um vínculo de afetividade. Quando ela diz "estamos nos gostando" mostra que o interesse um pelo outro é recíproco, mas só depois da relação "vai criando amizade", ou seja, ela vai se afeiçoando a ele pelo carinho que ele lhe dá que torna a relação sexual prazerosa, que "tem gosto".

Essa nova concepção de sexualidade surge quando a procriação não assume mais lugar central na atividade sexual, levando o indivíduo a buscar outras formas de realização no plano da intimidade e da afetividade. Bozon (2004, p. 43) refere que a sexualidade se torna "uma experiência pessoal, fundamental para a construção do sujeito, em um domínio que se desenvolveu e assumiu um peso considerável no decorrer dos séculos: a esfera da intimidade e da afetividade. O repertório sexual se ampliou [...] e as encenações da sexualidade se multiplicaram".

As próprias mudanças biofisiológicas retardam as respostas do corpo para chegar à lubrificação vaginal e à ereção peniana demandando, com isso, um investimento maior nas condições de excitação para que o corpo ative as funções que ordenem o coito. As carícias sexuais prolongam o ato sexual tornando-o mais satisfatório na velhice à medida que propicia 


\section{Revista \\ Debates Insubmissos}

aos sujeitos um conhecimento mais profundo do próprio corpo e do corpo do outro. Se na juventude e maturidade, o objetivo principal do sexo privilegiava a genitalidade, na velhice, a genitalidade só pode ser ativada se todo o corpo for doado em benefício da excitação.

Nesse momento de redescoberta da sexualidade, a velha precisa provar a sua feminilidade para se reafirmar como mulher enquanto ser sexuado que sente e desperta atração sexual. Ser mulher é ser desejada pelos atributos que denotam sedução. Ao chegar à velhice, a mulher é destituída de sua condição de gênero como se a aparência decrépita lhe retirasse a feminilidade, por isso, "a conservação do corpo atua no sentido de evitar o estigma da velha feia e caída" (NONATO e SASSAKI, 2016, p. 05). A feminilidade está ligada aos valores juvenis. Assim, é pelo corpo decrépito que se deixa de ser mulher, assim como é pelo corpo travestido de juvenilidade, que se volta a ser mulher.

A mudança na aparência é o passo inicial para comunicar a existência feminina e isso acontece por meio da adoção de estilos juvenis, pois remetem à ideia de beleza, sedução e vigor. As velhas de Parintins andam sempre arrumadas, com bermudas na altura dos joelhos, blusas de alcinhas, unhas pintadas e com o rosto maquiado. Mas, o adorno mais importante que elas carregam é o jeito espontâneo de ser, de dar risadas altas, de conversarem muito e de manterem o bom humor (Caderno de Campo, 2018). Após se afinarem novamente com a feminilidade socialmente valorizada, a validação precisa vir pelo olhar do outro.

A valorização sexual da mulher velha lhe remete ao tempo existencial de sua juventude, um tempo idílico, que a faz transgredir os comportamentos socialmente esperados para ela na velhice, como o pudor, o recato e a anulação de si em favor do outro, fazendo com que ela assuma, assim, um jeito mais despojado e sedutor. As narrativas da vida sexual dessas mulheres, assim como as dos homens velhos, também são contadas a partir da reconstituição que elas fazem das representações subjetivas do ato sexual e das diversas manifestações que envolvem a sua sexualidade que consumam no plano da liberdade em que elas vivem na velhice. Por isso, o romance e a paixão dão o tom de que o sexo está melhor em suas idades. 


\section{CONSIDERAÇÕES FINAIS}

Não é possível falar de sexualidade sem tocar nos aspectos de gênero e vice-versa. A sexualidade não é um assunto meramente biológico, é um tema político e cultural inscrito na história de vida das mulheres. Estamos falando de mulheres que elegeram a sexualidade como um ato de resistência para viver a plenitude de sua condição feminina até o fim da vida mesmo de terem sido longamente aviltadas de si e transformadas em objetos sexuais nas mãos de homens machistas.

A condição feminina é ressignificada na idade madura em virtude das mudanças processadas na forma de gestão da velhice no tempo contemporâneo. As mulheres conseguiram transitar do patriarcado à liberdade de gênero aceitando, sem resistência, as transformações no campo da sexualidade, pois entram em sintonia com a liberdade de gênero que conquistaram na velhice. Essa liberdade não é, apenas, uma liberdade concedida pela desobrigação em virtude da independência dos filhos e da separação conjugal dos seus maridos, mas é uma liberdade pessoal irrompida pelo espírito à medida que elas decidem transgredir os papéis de resignação e de invisibilidade esperados para a mulher velha.

\section{REFERÊNCIAS}

BAUMAN, Zygmunt; DESSAL, Gustavo. O retorno do pêndulo: sobre a psicanálise e o futuro do mundo líquido. Tradução Joana Angélica d'Ávila Melo. Rio de Janeiro: Zahar, 2017 ;

BEAUVOIR, Simone de. O Segundo Sexo - Vol. 2 - A experiência vivida. Tradução de Sérgio Milliet. $3^{\mathrm{a}}$ edição. Rio de Janeiro: Nova Fronteira, 2016;

BRIGEIRO, Mauro; MAKSUD, Ivia. Aparição do Viagra na cena pública brasileira:

discursos sobre corpo, gênero e sexualidade na mídia. Revista Estudos Feministas, n. 17, vol. 1. Florianópolis, 2009;

BOURDIEU, Pierre. A dominação masculina. Tradução: Maria Helena Kühner. $3^{\mathrm{a}}$ ed. Rio de Janeiro: BestBolso, 2016;

BOZON, Michel. Sociologia da sexualidade. Tradução: Maria de Lourdes Menezes. Rio de Janeiro: Editora FVG, 2004; 
BUTLER, Judith. Problemas de gênero: feminismo e subversão da identidade. Tradução de Renato Aguiar. 17ª edição. Rio de Janeiro: Civilização Brasileira, 2019;

DEBERT, Guita Grin. A invenção da terceira idade e a rearticulação de formas de consumo e demandas políticas. Revista Brasileira de Ciências Sociais, vol. 12, n. 34. São Paulo, 1997;

DEBERT, Guita Grin. Gênero e Envelhecimento. Revista Estudos Feministas, v. 2, n. 3, Florianópolis, 1994;

DEL PRIORE, Mary. História do amor no Brasil. $3^{\text {a }}$ edição. São Paulo: Contexto, 2015;

GAGNON, John H. Uma interpretação do desejo: ensaios sobre o estudo da sexualidade. Tradução de Lúcia Ribeiro da Silva. Rio de Janeiro: Garamond, 2006;

GIDDENS, Anthony. A transformação da intimidade: sexualidade, amor e erotismo nas sociedades modernas. Tradução de Magda Lopes. São Paulo: Editora da Universidade Estadual Paulista, 1993;

GOLDENBERG, Mirian. Coroas. Rio de Janeiro: BestBolso, 2015;

GOLDENBERG, Mirian. A bela velhice. $5^{\text {a }}$ edição. Rio de Janeiro: Record, 2014;

LEÃO, Alice Alves Menezes Ponce de. Serviço Social e Velhice: perspectivas para o trabalho do assistente social na promoção à saúde do idoso. Manaus: EDUA, 2015;

LISPECTOR, Clarice. Mas vai chover. In: A via crucis do corpo (contos). Rio de Janeiro, Rocco, 1998;

MERLEAU-PONTY, Maurice. Fenomenologia da percepção. Tradução de Carlos Alberto Ribeiro de Moura. $2^{a}$ edição. São Paulo: Martins Fontes, 1999;

MORIN, Edgar. O método 5: a humanidade da humanidade. Tradução de Juremir Machado da Silva. $5^{\text {a }}$ edição. Porto Alegre: Sulina, 2012;

MOTTA, Alda Brito. As dimensões de gênero e classe social na análise do envelhecimento. Revista Cadernos Pagu, n. 13, Campinas, 1999;

NONATO, Alice Alves Menezes Ponce de Leão; SASSAKI, Yoshiko. Um retrato da sexualidade da mulher idosa no conto "Mas vai chover", de Clarice Lispector. Revista Graphos, vol. 18, n. 1, 2016;

PASCUAL, Cosme Puerto. A sexualidade do idoso vista com novo olhar. Tradução de Alda da Anunciação Machado. São Paulo: Edições Loyola, 2002;

PATEMAN, Carole. O contrato sexual. Tradução: Marta Avancini. Rio de Janeiro: Paz e Terra, 1993; 
PINSKY, Carla Bassanezi. Mulheres dos anos dourados. In: DEL PRIORE, Mary. História das mulheres no Brasil. $10^{a}$ edição. São Paulo: Contexto, 2017;

PONCE DE LEÃO NONATO, Alice Alves Menezes. Sexo e sexualidade na velhice: práticas transgressoras e negociadas no contexto amazônico. Tese de doutorado. Universidade Federal do Amazonas, 2018;

REED, Evelyn. Sexo contra sexo ou classe contra classe. 12a edição. São Paulo: Editora Instituto José Luís e Rosa Sundermann, 2008;

RIBEIRO, Euler Esteves. Envelhescência: Envelhecer bem e com qualidade! Rio de Janeiro: UnATI/UERJ, 2008;

RIBEIRO, Alda. Sexualidade na Terceira Idade. In: Gerontologia: a velhice e o envelhecimento em visão globalizada. NETTO, Matheus Papaléo (org.). São Paulo: Editora Atheneu, 2005;

ROIZ, Diogo da Silva. A história do corpo feminino e masculino no ocidente medieval. Cadernos Pagu, volume 33, Campinas (SP), 2009.

SHEEHY, Gail. O sexo e a mulher madura - em busca das paixões da vida. Tradução de Waldéa Barcellos. Rio de Janeiro: Rocco, 2008;

SCOTT, Joan. Gênero: uma categoria útil de análise histórica. Tradução de Christine Rufino Dabat e Maria Betânia Ávila. Recife: SOS Corpo, 1991.

Submetido em: $30 / 06 / 2020$

Aprovado em: 20/07/2020 